\title{
Inhibition of Submandibular and Lacrimal Gland Infiltration in Nonobese Diabetic Mice by Transgenic Expression of Soluble TNF-receptor p55
}

\author{
Robert E. Hunger, ${ }^{\star}$ Stefan Müller, ${ }^{\star}$ Jean A. Laissue, ${ }^{*}$ Max W. Hess, ${ }^{\star}$ Claude Carnaud, ${ }^{\ddagger}$ Irene Garcia, ${ }^{\S}$ and Christoph Mueller ${ }^{\star}$ \\ *Department of Pathology, University of Bern, CH-3010 Bern, Switzerland; ${ }^{\ddagger}$ Institut National de la Santé et de la Recherche Médicale \\ U25, Hôpital Necker, 75743 Paris Cedex 15, France; and ${ }^{\S}$ Department of Pathology, CMU, CH-1211 Geneva, Switzerland
}

\begin{abstract}
Besides a prominent mononuclear cell infiltration of the islets of Langerhans, nonobese diabetic (NOD) mice also show massive cellular infiltrates of the submandibular and lacrimal glands concomitant with histological signs of tissue damage. To obtain insights into the mechanisms operative during the initiation and progression of tissue damage, we followed by in situ hybridization the appearance of cells containing mRNA of the gene encoding the proinflammatory cytokine TNF- $\alpha$ in the cellular infiltrates. Cells expressing TNF- $\alpha$ are mainly located in infiltrates, are absent in nonaffected glands, and are preferentially found among $\mathrm{CD}^{+}{ }^{+} \mathrm{T}$ cells. Secretion of TNF- $\alpha$ by gland-infiltrating cells was confirmed by an ELISPOT procedure. Direct evidence for an instrumental role of TNF- $\alpha$ in initiation and progression of submandibular and lacrimal gland infiltration is provided by the observed significant reduction in the extent of infiltration in nonobese diabetic mice transgenic for a soluble TNF receptor p55 fused to the Fc part of human IgG3. This protection from infiltration is paralleled by decreased expression of the adhesion molecules ICAM-1 and VCAM-1 in submandibular and lacrimal glands. These data suggest a central role of TNF- $\alpha$ in the initiation and progression of autoimmune tissue destruction of salivary glands and indicate beneficial effects of soluble TNF receptors in the treatment of organ-specific autoimmune diseases. (J. Clin. Invest. 1996. 98:954-961.) Key words: cell adhesion molecules - Sjögren's syndrome • autoimmune diseases • sialadenitis • tumor necrosis factor- $\alpha$
\end{abstract}

\section{Introduction}

In addition to its well-established role as an animal model for insulin-dependent diabetes mellitus (IDDM), ${ }^{1}$ the nonobese

Address correspondence to Christoph Mueller, Department of Pathology, University of Bern, Murtenstrasse 31, CH-3010 Bern, Switzerland. Phone: 413163289 04; FAX: 413138187 64; E-mail: muellerc@patho.unibe.ch

Received for publication 19 March 1996 and accepted in revised form 13 June 1996.

1. Abbreviations used in this paper: IDDM, insulin-dependent diabetes mellitus; NOD mouse, nonobese diabetic mouse; TNFR, TNFreceptor; sTNFR p55-h $\gamma 3$, soluble TNFR p55 fused to the Fc part of human IgG3.

J. Clin. Invest.

(C) The American Society for Clinical Investigation, Inc.

0021-9738/96/08/0954/08 \$2.00

Volume 98, Number 4, August 1996, 954-961 diabetic (NOD) mouse has also been proposed as a valid animal model for Sjögren's disease due to the spontaneous occurrence of lymphocytic infiltrates of the submandibular and lacrimal glands (1). Unlike other mouse strains with reported infiltration of the salivary glands, such as MLR/lpr, MLR/+ and $(\mathrm{NZB} \times \mathrm{NZW}) \mathrm{F} 1$ mice (2), dysfunctions of salivary glands are observed in NOD mice concomitant with progressive cellular infiltration and tissue destruction of these organs (3). Data on possible mechanisms operative in the initiation and progression of tissue destruction in salivary glands of mice are very limited thus far and mostly restricted to the analysis of the submandibular glands. However, several previous reports, such as experiments using adoptive cell transfer (4) and electron microscopy analysis $(5,6)$, provide circumstantial evidence for a cell-mediated autoimmune pathogenesis in salivary gland destruction. Humoral immune mechanisms are considered less important for tissue damage since the presence of antiductal cell antibodies is not associated with histological signs of tissue destruction (5).

TNF- $\alpha$ has been found in virtually all inflammatory processes analyzed so far (7) and there are several different possibilities how TNF- $\alpha$ promotes the inflammatory process. First, TNF- $\alpha$ has been described to upregulate the expression of cell adhesion molecules such as ICAM-1, VCAM-1, and MAdCAM-1 (8). This may lead to increased recruitment of inflammatory cells to the sites of inflammation. Second, TNF- $\alpha$ has been shown to upregulate the expression of MHC class I and II molecules (7). Third, in addition to its proinflammatory properties, TNF- $\alpha$ can exert cytotoxic activity against several target cells, including pancreatic $\beta$ cells. This has been observed for TNF- $\alpha$ and the structurally and functionally related TNF- $\beta$ (lymphotoxin- $\alpha$ ) either alone or in synergy with other cytokines; in particular, IL-1 and interferon- $\gamma$ (9). Involvement of TNF- $\alpha$ as a mediator of cell-mediated cytotoxicity is also suggested by the structural similarities between TNF-receptor (TNFR) p55 and Fas; both share a homology region supposedly involved in mediating an apoptotic signal (death signaling domain) (10).

Thus far, studies on the role of TNF in the pathophysiology of disease in the NOD mouse mainly focused on its role in the development of IDDM. However, discrepant observations were made after injection of TNF, or of anti-TNF antibodies, to newborn and adult NOD mice. Injection of $\mathrm{TNF}_{-} \alpha$ into newborn female NOD mice was found to accelerate disease development (11), whereas administration to adult animals was inhibitory (12). Moreover, experiments involving neutralization of TNF- $\alpha$ with specific antibodies revealed both diabetes-protecting (12) and diabetes-promoting effects (13).

To circumvent the difficulties encountered with the use of recombinant TNF- $\alpha$ or injection of antibodies against TNF to assess the contribution of TNF- $\alpha$ in the pathogenesis of disease, we generated NOD mice transgenically expressing sTNFR p55-h $\gamma 3$ under the control of the $\alpha$-1-antitrypsin promoter. 


\section{Methods}

Mice. NOD mice were originally purchased from Bomholtgard Breeding and Research Centre Ltd. (Ry, Denmark) and were bred and kept under conventional conditions in our animal facility. Mice were regularly tested and found to be serologically negative for the presence of mouse hepatitis and Sendai viruses. Male and female NOD mice were killed at 2, 4, 6, 8, 12, and $18 \mathrm{wk}$ of age, or after onset of diabetes (median $25.5 \mathrm{wk}$, range 21-26 wk). Mice were classified as diabetic after producing glucosuria with consistent Tes-Tape (Eli Lilly and Co., Indianapolis, IN) values of $\geq 2+$.

Generation of sTNFR p55- $h \gamma 3$-expressing NOD mice. A transgenic C57BL/6F2 mouse expressing high levels of sTNFR p55-h $\gamma 3$ under the control of the $\alpha$-1-antitrypsin promoter (14) was mated with female NOD mice. F1 males were subsequently backcrossed to NOD mice resulting in $\mathrm{BC} 1$ generation. To generate $\mathrm{BC} 2$ animals, a $\mathrm{BC} 1$ female expressing sTNFR p55-h $\gamma 3$ was mated with a male NOD mouse. For all other backcrosses, male transgenic animals were mated with female NOD mice. Homozygosity for $\mathrm{H}-2^{\text {nod }}$ was fixed at $\mathrm{BC} 3$. $\mathrm{BC} 2$ mice were screened by PCR amplification of Hsp- 68 microsatellite (primers and protocol for PCR kindly provided by H.-J. Garchon). This genetic marker is located within the MHC class III region at a short distance from the Idd1 locus and, therefore, indicating with high probability homozygosity for Idd1. Further evidence for homozygosity of the Idd1 locus is provided by the fact that transgenenegative littermates of BC6 generation show identical diabetes incidence as age- and sex-matched wild-type NOD mice in our colony (Hunger, R.E., C. Carnaud, I. Garcia, P. Vassalli, and C. Mueller, manuscript submitted for publication). Homozygosity at the Idd1 locus is a prerequisite for the development of IDDM (15). No further genetic markers were analyzed during the backcrossing. Although BC3 animals show histological signs of mononuclear cell infiltration of pancreatic islets, submandibular and lacrimal glands, these inflammatory infiltrates are less prominent than in wild-type NOD mice of our colony. In BC3 animals, the amount of non-NOD genetic background still present can be calculated to represent $\sim 9 \%$ (16). Transgene-negative animals of BC5 generation, however, show the same extent of infiltration in pancreatic islets and submandibular and lacrimal glands as age- and sex-matched NOD mice. Therefore, animals of BC6 and BC7 generation have been included in the present study. At this stage of backcrossing, the amount of non-NOD genetic background still present is estimated to be $\sim 2 \%$. This includes about 25 centimorgan of genetic material selected with the transgene (16).

Activity of the $\alpha$-1-antitrypsin promoter in a transgenic mouse system has been reported already on day 12.5 of gestation (17). Therefore, production of transgenic sTNFR p55-h $\gamma 3$ is very likely to occur already in utero. This is further supported by the observation that neonates of BC6 generation show considerable amounts (10-20 $\mu \mathrm{g} / \mathrm{ml}$ ) of sTNFR p55-h $\gamma 3$ in the serum and reach adult levels of 400$1,000 \mu \mathrm{g} / \mathrm{ml}$ at $3 \mathrm{wk}$ of age.

Detection of sTNFR p55-h $\gamma 3$. Mice were bled at 6 to $8 \mathrm{wk}$ of age and the concentrations of blood sTNFR p $55-\mathrm{h} \gamma 3$ were evaluated by ELISA as previously described (14).

Determination of TNF-neutralizing capacity. TNF-neutralizing capacity of transgenic sera was assessed using a modified procedure described for TNF- $\alpha$ bioassays (18). Briefly, 96-well plates (Costar Corp., Cambridge, MA) coated with $4 \times 10^{4}$ L929 cells per well were incubated overnight at $37^{\circ} \mathrm{C} / 5 \% \mathrm{CO}_{2}$ with serial dilutions of mice sera, preincubated with recombinant TNF- $\alpha$ (Innogenetics, Antwerp, Belgium $)$ in the presence of actinomycin D $(4 \mu \mathrm{g} / \mathrm{ml})$. Plates were subsequently stained with crystal violet and dried overnight. $100 \mu \mathrm{l}$ methanol per well was added to solubilize the dye. TNF- $\alpha$ concentration was assessed by determining absorbance with an ELISA reader at $595 \mathrm{~nm}$.

Tissue processing. Tissue specimens of submandibular salivary gland and extraorbital lacrimal gland were embedded in ornithine carbamyl transferase compound (Miles Laboratories, Inc., Elkhart, IN), together with specimens from spleen and small intestine as controls, and stored at $-70^{\circ} \mathrm{C}$. Pancreatic tissues were immersed in $4 \%$ paraformaldehyde in PBS followed by routine processing for paraffin embedding.

Preparation of ${ }^{35}$ S-labeled $R N A$ probes. A 1,108 -bp cDNA fragment of the murine TNF- $\alpha$ gene (positions 1-1,108; obtained from Genentech Inc., South San Francisco, CA) (19) was subcloned into pGEM-2. After linearization of the plasmid, sense and antisense RNA probes were prepared using SP6 and T7 polymerase reactions, respectively, with ${ }^{35} \mathrm{~S}$-labeled CTP as previously described (20).

In situ hybridization. Serial frozen sections of submandibular gland, lacrimal gland, spleen, and small intestine tissues were hybridized in situ with an antisense RNA probe for TNF- $\alpha$ gene and, as a control, a sense gene. In situ hybridization was performed as previously described in detail (20). Briefly, cryostat sections were fixed in $4 \%$ paraformaldehyde in PBS for $20 \mathrm{~min}$ at room temperature, rinsed in PBS, and subsequently treated with proteinase $\mathrm{K}$ (Boehringer Mannheim, Mannheim, Germany) at $1 \mu \mathrm{g} / \mathrm{ml}$ at $37^{\circ} \mathrm{C}$ for $30 \mathrm{~min}$. After postfixation and acetylation, hybridization was performed with $2 \times 10^{5} \mathrm{cpm}$ of ${ }^{35} \mathrm{~S}$-labeled RNA probe per microliter of hybridization solution for $18 \mathrm{~h}$ at $48^{\circ} \mathrm{C}$. After digestion of single-stranded, nonhybridized RNA and extensive washing, slides were dipped in NTB2 nuclear track emulsion (Eastman Kodak Co., Rochester, NY). Slides were exposed for $28 \mathrm{~d}$ in a light-tight box at $4^{\circ} \mathrm{C}$, developed, and subsequently counterstained with nuclear fast red $(0.05$ in $5 \%$ aluminum sulfate) by standard techniques.

Immunohistochemistry. Serial frozen sections of submandibular salivary and lacrimal glands (and as controls, spleen and small intestine tissues) were stained with the rat anti-mouse CD54 (ICAM-1) monoclonal antibody or biotinylated hamster anti-mouse CD106 (VCAM-1) monoclonal antibody (both obtained from PharMingen, San Diego, CA) as a first-stage reagent. As second-stage reagents, peroxidase-conjugated rabbit anti-rat immunoglobulin (DAKOPATTS, Copenhagen, Denmark) at a 1:25 dilution in 10\% normal mouse serum, or peroxidase-conjugated avidin-biotin complexes (ABComplex/HRP; DAKOPATTS) were used. 3,3'-diaminobenzidine (Sigma Chemical Co., St. Louis, MO) was used as a substrate for peroxidase. Sections were counterstained for 10 min with $4 \%$ Giemsa (Merck, Darmstadt, Germany) in PBS.

Isolation of infiltrating cells. For the isolation of submandibular gland- and lacrimal gland-infiltrating cells, submandibular glands of three female and lacrimal glands of three male NOD mice were excised and teased into small pieces. Care was taken not to include cervical lymph nodes. Single cell suspensions were prepared by carefully disrupting the tissue pieces between frosted ends of two microscope slides. Erythrocytes were removed by osmotic shock according to standard protocol. Single cell suspensions of spleen were prepared by standard techniques. Isolated cells were subsequently incubated on ice for 30 min with FITC-coupled anti-Thy-1.2 antibody (53-2.1; fluoresceinated according to standard protocol) and PE-coupled antiCD4 antibody (GK1.5; Becton Dickinson, San Jose, CA). After completion of the staining procedure, cells were fixed in freshly prepared $4 \%$ buffered PFA. A FACS ${ }^{\circledR}$ Vantage Cell Sorter (Becton Dickinson) was used for the separation of $\mathrm{CD} 4^{+}$Thy $1.2^{+}$cells after gating the lymphoid cell population, based on forward and side light scatter of the isolated cell population. For control purposes, the unfractionated lymphoid cell population, defined only by their forward and side light scatter gating, was also collected. The cell populations were directly sorted onto poly L-lysine-coated microscope slides (Menzel Gläser, Braunschweig, Germany), using the automatic cell deposition unit (ACDU) and software (Becton Dickinson). In situ hybridization of sorted cells was performed as described above for tissue sections.

Evaluation of in situ hybridization. Cells were considered positive for expression of the TNF- $\alpha$ gene when they had at least twice as many silver grains as the cells with the highest background on control slides that were hybridized with a labeled sense probe (identical sequence to the cellular target mRNA). Generally, tissue sections hybridized with sense probes showed less than four grains per cell after a 4-wk exposure, and no evidence for nonspecific binding of radiolabeled probes to tissue sections or isolated cells was found. 
Histopathological evaluation of tissue sections. The extent of inflammatory infiltrates in submandibular and lacrimal glands was estimated by measuring the area of mononuclear infiltrates on tissue sections of the entire organ using an image analysis system (Mocha V.1.10 image analysis software; Jandel Scientific, SanRafael, CA). Infiltration was expressed as percent of total area occupied by infiltrating mononuclear cells.

Evaluation of immunohistochemical stainings. For each mouse, two non-serial tissue sections were stained and vessels expressing VCAM-1 or ICAM-1 were counted under a microscope.

Enumeration of TNF- $\alpha$-producing cells. To determine the number of TNF- $\alpha$-producing cells among organ-infiltrating cells, an ELISPOT assay was performed as previously described (21) with the only modification being that Tween was used at a concentration of $0.025 \%$. Briefly, after coating with monoclonal hamster anti-mouse TNF- $\alpha$ (Genzyme Corp., Cambridge, MA) at $4^{\circ} \mathrm{C}$ overnight at a concentration of $5 \mu \mathrm{g} / \mathrm{ml}$, nitrocellulose-backed microtiter plates (96 well; Millipore Corp., Bedford, MA) were blocked with Tris buffered saline (TBS) containing 5\% BSA. After washing the plates with TBS containing $0.025 \%$ Tween (TBS-Tween), freshly isolated infiltrating cells of submandibular and lacrimal glands, respectively, and control splenocytes of the same animals were incubated in DMEM containing $5 \% \mathrm{FCS}$ for $6 \mathrm{~h}$ at $37^{\circ} \mathrm{C}$ with $5 \% \mathrm{CO}_{2}$ in air. The plates were extensively washed with TBS-Tween and incubated overnight at $4^{\circ} \mathrm{C}$ with biotinylated rabbit anti-mouse TNF- $\alpha$ polyclonal antibody (PharMingen) at a concentration of $2 \mu \mathrm{g} / \mathrm{ml}$. After washing with TBS-Tween, the wells were incubated with avidin-alkaline phosphatase (Sigma Chemical Co.) diluted 1:2,000 for $2 \mathrm{~h}$ at room temperature, washed again, and developed with 5-bromo-4-chloro-3-indoyl phosphate/nitroblue tetrazolium (BCIP/NBT) solution (Kirkegaard and Perry Laboratories, Inc., Gaithersburg, MD). After development, positive spots were counted under a dissecting microscope.

\section{Results}

TNF- $\alpha$ mRNA is expressed during infiltration of submandibular and lacrimal glands of NOD mice. To characterize functions exerted by submandibular and lacrimal gland-infiltrating cells, in situ hybridization for the specific detection of TNF- $\alpha$ mRNA was performed. The histological assessment of the mononuclear infiltration of the submandibular and lacrimal glands in our conventional NOD colony revealed that in con- trast to pancreatic and submandibular gland infiltration, which progresses more rapidly in female than in male NOD mice, the lacrimal gland infiltration is more pronounced in male NOD mice. Onset of cellular infiltration of the lacrimal gland is delayed in female NOD mice compared to their male littermates, despite the presence of massive cellular infiltrates in the islets of Langerhans and submandibular glands. Already at 6 wk of age, all male NOD mice show early signs of lacrimal gland infiltration. Infiltration rapidly increases with age and at $18 \mathrm{wk}$, $\sim 20 \%$ of the whole tissue section is occupied by mononuclear infiltrating cells. This infiltration leads in the majority of male mice at $30 \mathrm{wk}$ of age to an almost complete destruction of the glandular acini. A similar situation is observed in the submandibular glands of female NOD mice. The first signs of infiltration are detected at $6 \mathrm{wk}$ of age in $\sim 50 \%$ of the animals. At $8 \mathrm{wk}$, all animals show infiltration that continues to increase with age. At $18 \mathrm{wk}, \sim 5 \%$ and at $30 \mathrm{wk}$, up to $35 \%$ of the whole tissue section is occupied by mononuclear infiltrating cells (Hunger, R.E., C. Carnaud, C. Mueller, unpublished data). Therefore, we separately determined the appearance of TNF- $\alpha$ mRNA-expressing cells in female and male NOD mice (Fig. 1, $A$ and $B$ ). Concomitant with the first histological signs of submandibulitis in female, and of cellular infiltration of the lacrimal glands in male NOD mice, TNF- $\alpha$ mRNA-positive cells are detected in the infiltrated organs in significant numbers (Fig. 1, $A$ and $B$ ). However, during the entire 18-wk observation period, only low numbers of TNF- $\alpha$ mRNA-containing cells were found in submandibular glands of male NOD mice. In the lacrimal glands of female NOD mice, low numbers of TNF- $\alpha$-expressing cells were found only at the latest time point examined; i.e., at 18 wk of age. A majority of these TNF- $\alpha$ mRNA-containing cells $(>90 \%)$ are close to, or even in direct contact with, remaining salivary or lacrimal gland parenchymal cells. An example of a tissue section hybridized in situ with a radiolabeled RNA probe for detection of TNF- $\alpha$ mRNA is shown in Fig. $2 A$ for the submandibular gland and in Fig. $2 B$ for the lacrimal gland. Control slides hybridized with sense RNA probes show no accumulation of silver grains (Fig. 2, C and $D)$. Despite the rapid progression of mononuclear cell infiltration, the frequency of TNF- $\alpha$-expressing cells on entire
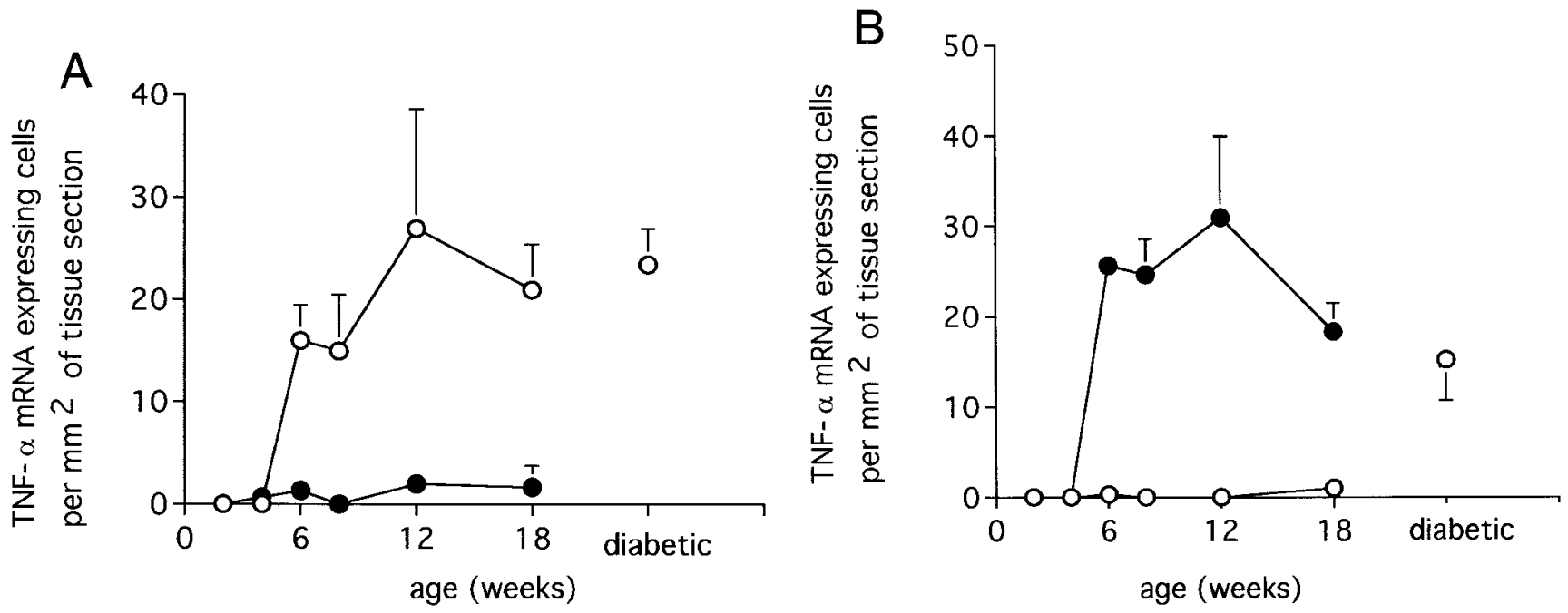

Figure 1. Number of TNF- $\alpha$ mRNA-expressing cells per $\mathrm{mm}^{2}$ of tissue cross section of $(A)$ submandibular glands and $(B)$ lacrimal glands from NOD mice. At each time point, three female (open circles) and three male (closed circles) NOD mice were evaluated $( \pm$ SEM). 

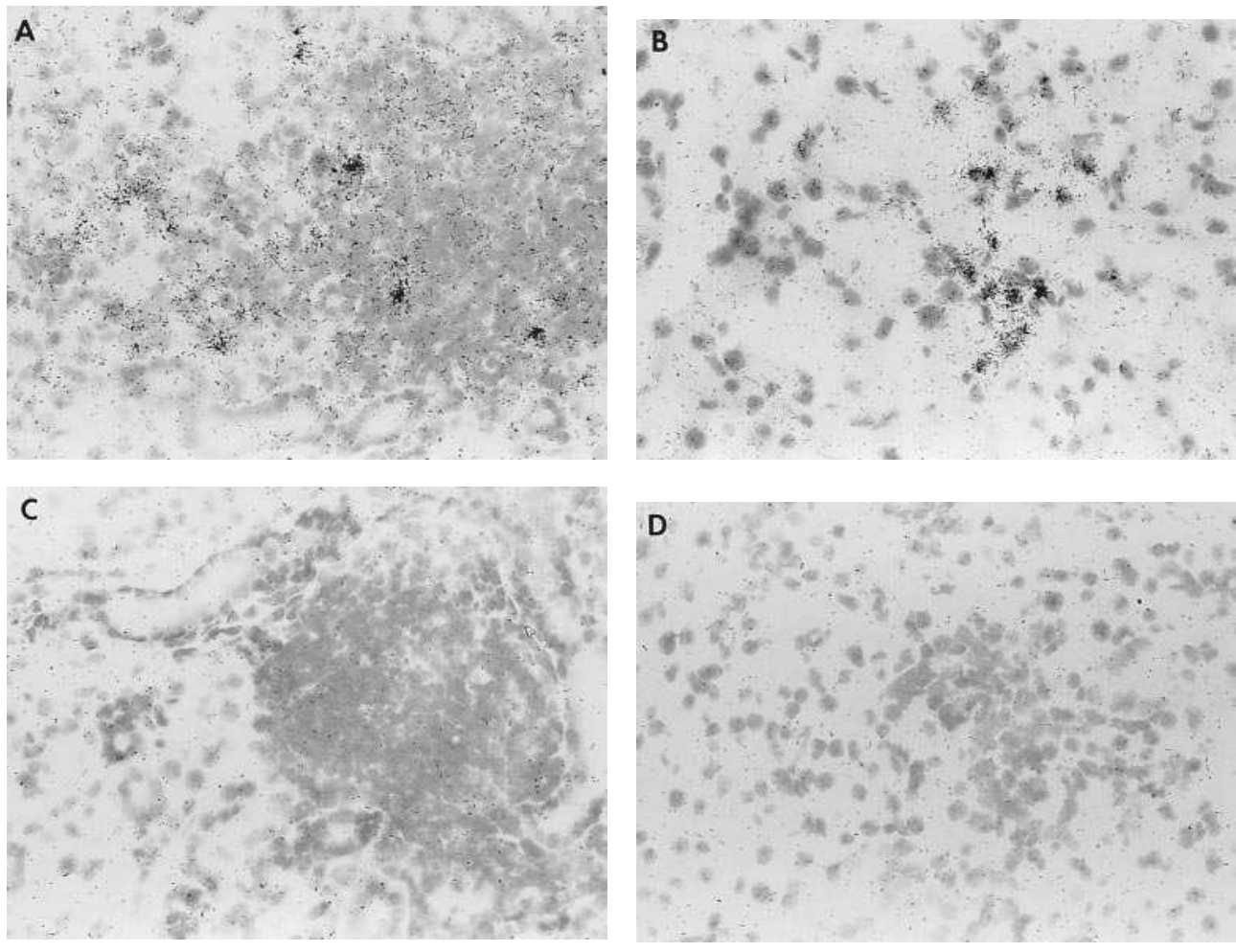

Figure 2. In situ hybridization of cryostat sections. $(A$ and $C$ ) Submandibular gland of a 26 -wk-old female NOD mouse. $(B$ and $D)$ Lacrimal gland of a 6-wk-old male NOD mouse. $A$ and $B$ are hybridized with ${ }^{35}$ S-labeled antisense RNA probes for the detection of TNF- $\alpha ; C$ and $D$ are a semiserial tissue section hybridized with ${ }^{35}$ S-labeled RNA sense probes, as negative controls.

cross sections of these two glands remains either constant (in submandibular glands of female NOD mice, Fig. $1 A$ ), or even decreases slightly (in lacrimal glands of male NOD mice, Fig. 1 $B$ ). This demonstrates that maximum frequency of TNF- $\alpha$ mRNA-expressing cells in the cellular infiltrates are present during the early phase of inflammatory infiltration.

$T N F-\alpha$ is preferentially expressed by gland-infiltrating $C D 4^{+}$ $T$ cells. To obtain some information on the phenotype of the TNF- $\alpha$-expressing cells in the cellular infiltrates, submandibular and lacrimal gland-infiltrating cells were isolated as described, stained with appropriate antibodies, fixed with paraformaldehyde, and sorted directly onto glass slides for subsequent in situ hybridization. This procedure was required since a combination of immunostaining and in situ hybridization could not be accomplished without significant loss of signals due to different fixation requirements. As shown in Fig. 3, the $\mathrm{CD}^{+}{ }^{+} \mathrm{T}$ cell subset that represents $\sim 30 \%$ of the isolated submandibular gland-infiltrating cells, and $\sim 20 \%$ of the isolated cells from infiltrated lacrimal glands, are highly enriched for TNF- $\alpha$ mRNA-expressing cells, whereas in splenocytes of the same animals, no preferential expression of $\mathrm{TNF}_{-} \alpha$ in $\mathrm{CD}^{+}{ }^{+} \mathrm{T}$ cells is observed. In addition to the $\mathrm{CD}^{+} \mathrm{T}$ cell subset, cytofluorometric analysis revealed the presence of $4-10 \%$ $\mathrm{CD}^{+} \mathrm{T}$ cells in the cellular infiltrates. The majority of the remaining salivary and lacrimal gland-infiltrating cells are $\mathrm{B} 220^{+}$ cells (B cells); macrophages and granulocytes constitute only minor subsets in the infiltrates.

Gland-infiltrating cells produce TNF- $\alpha$ also on a protein level. To confirm that TNF- $\alpha$ is actually produced and secreted by these infiltrating cells, an ELISPOT assay was performed with isolated submandibular and lacrimal gland-infiltrating cells from NOD mice. In two independent experiments using submandibular gland-infiltrating cells of three female NOD mice (age $>10 \mathrm{wk}$ ) and lacrimal gland-infiltrating cells of three male NOD mice (age $>10 \mathrm{wk}$ ), an average of 10.6 TNF- $\alpha$-producing cells per 1,000 cells was detected. Cells infiltrating lacrimal or submandibular glands do not differ significantly in this respect. In comparison, the spleen of the same three groups of animals contained an average of 4.0 TNF- $\alpha-$ producing cells per 1,000 cells.

sTNFR p55-hy3-expressing NOD mice show reduced infiltration to submandibular and lacrimal glands. To further analyze the function of $\mathrm{TNF}-\alpha$ in the inflammatory infiltration of submandibular and lacrimal glands, mice transgenic for an sTNFR p55-h $\gamma 3$ were backcrossed into the genetic NOD background. Animals of the BC6 generation of NOD mice, heterozygous for the transgene, consistently show significant amounts of sTNFR p55-h $\gamma 3$ in the serum. As assessed in a

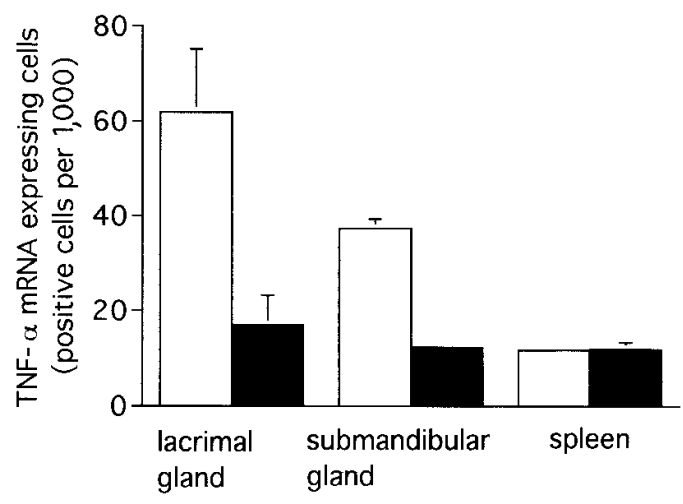

Figure 3. Relative frequency of TNF- $\alpha$ mRNA-expressing cells in isolated $\mathrm{CD}^{+}{ }^{+}$Thy $1.2^{+} \mathrm{T}$ cells (open bar), and in the isolated, unfractionated lymphoid cell population, defined only by their forward and side light scatter gating (filled bar), as determined in three independent experiments $( \pm$ SEM $)$. 

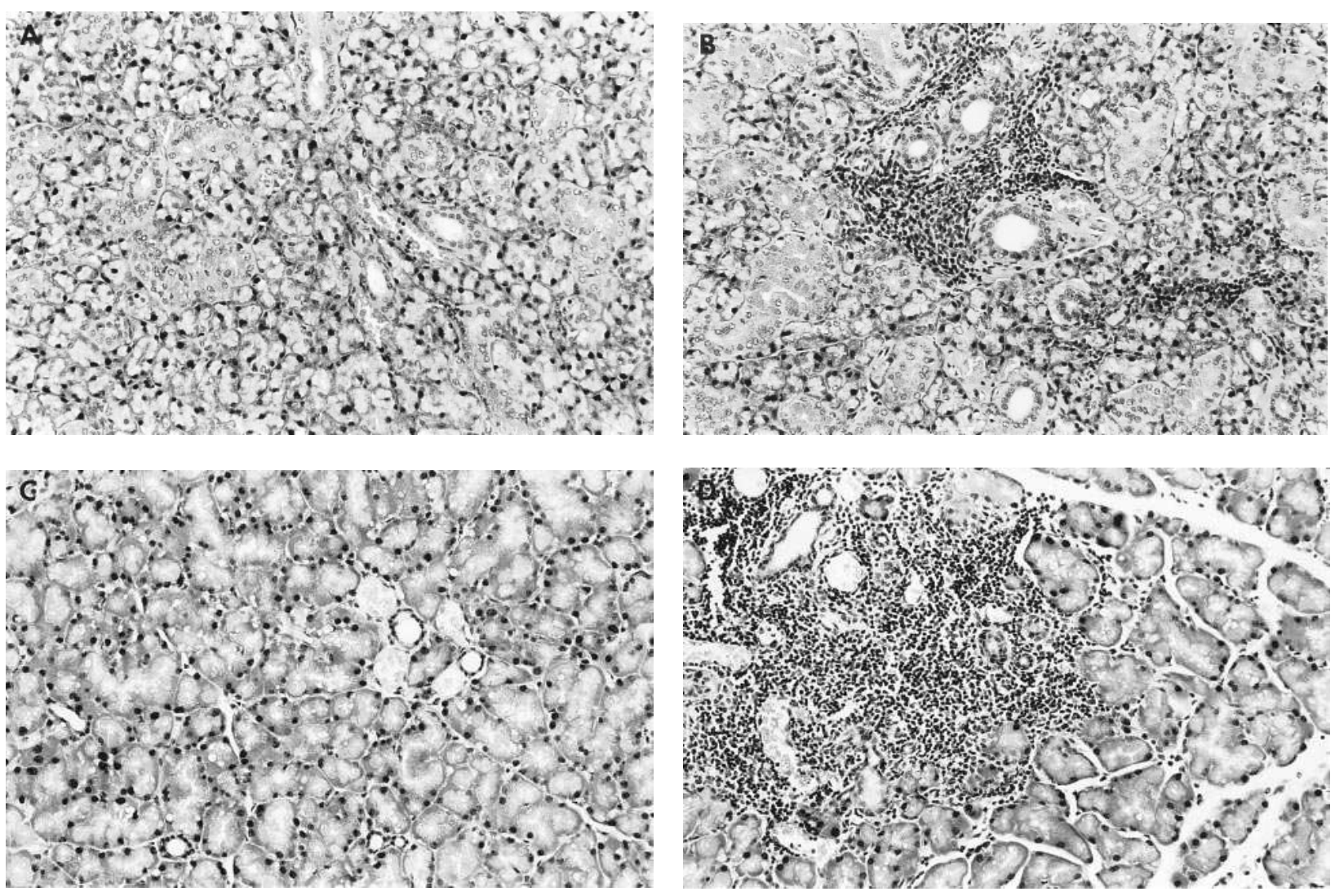

Figure 4. Representative tissue sections stained with hematoxilin and eosin. ( $A$ and $B$ ) Submandibular gland of a 12-wk-old sTNFR p55-hy3expressing female NOD mouse $(A)$ and a transgene negative littermate $(B)$. ( $C$ and $D)$ Lacrimal gland of a 12-wk-old sTNFR p55-h $\gamma 3$-expressing male NOD mouse $(C)$ and a transgene negative littermate $(D)$.

TNF bioassay, $1 \mathrm{ml}$ of transgenic serum neutralizes about 400 ng $(40,000 \mathrm{U})$ of bioactive TNF- $\alpha$. Due to the lower serum level of the transgenic fusion protein at birth, $1 \mathrm{ml}$ of serum from newborn transgenic mice neutralizes only about $1,000 \mathrm{U}$ of bioactive TNF- $\alpha$. The transgene-negative animals of the BC6 generation show the same diabetes incidence as our wildtype NOD mice, whereas the sTNFR p55-h $\gamma 3$-expressing NOD mice are completely protected from diabetes. Furthermore, the mononuclear infiltration to the islets is greatly reduced in sTNFR p55-hy3-expressing NOD mice (Hunger, R.E., C. Carnaud, I. Garcia, P. Vassalli, and C. Mueller, manuscript submitted for publication). As shown in Fig. 4, considerable infiltration by mononuclear cells is present in salivary glands of nontransgenic littermates, whereas cellular infiltrates are not consistently found in sTNFR p55-hy3-expressing NOD mice. To quantitate these observations, the infiltrated area was measured for each gland on two nonserial tissue sections using an image analysis system. The relative extent of infiltration in sTNFR p55-h $\gamma 3$-expressing animals compared to their transgene-negative littermates is indicated in Fig. 5. At each time point examined, a significant reduction of infiltration by $75-95 \%$ is observed in submandibular glands of female NOD mice as well as in lacrimal glands of male NOD mice.

Expression of the cell adhesion molecules VCAM-1 and ICAM-1 is reduced in submandibular and lacrimal glands of sTNFR p55-hy3-expressing NOD mice. To examine the effect of transgenic sTNFR p55-h $\gamma 3$ on the expression of the adhesion molecules VCAM-1 and ICAM-1 in salivary and lacri-

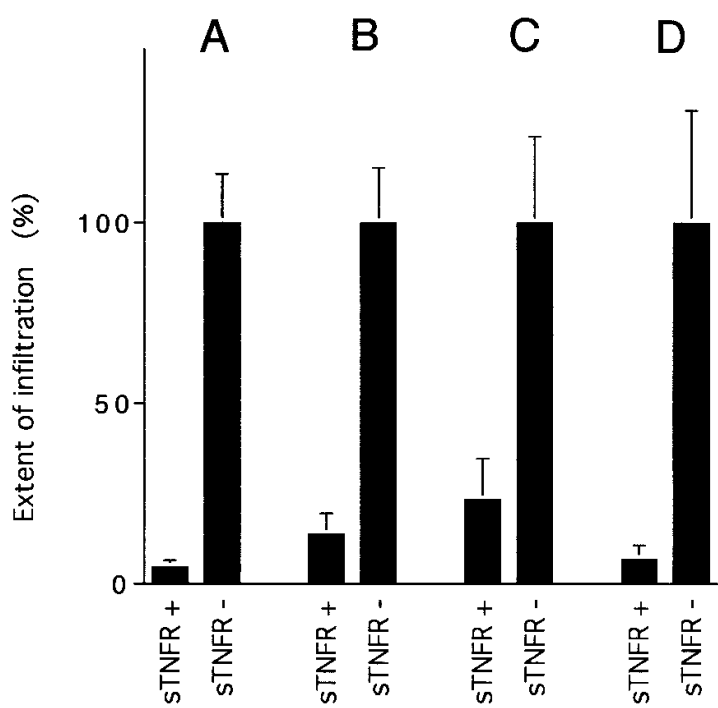

Figure 5. Quantitative evaluation of submandibular and lacrimal gland infiltration in sTNFR p55-h $\gamma 3$-expressing NOD mice $(s T N F R+)$ and their transgene-negative littermates (sTNFR-). The extent of inflammatory infiltrates was estimated by measuring the area occupied by mononuclear infiltrating cells using an image analysis system. The values were normalized (mean infiltration of transgene negative littermates $=100 \% \pm$ SEM). Submandibular glands of $(A)$ 12- and $(B)$ 28-wk-old female NOD mice. Lacrimal glands of $(C) 12$ - and $(D) 18$-wk-old male NOD mice. For each value, four to seven animals were analyzed ( \pm SEM). 

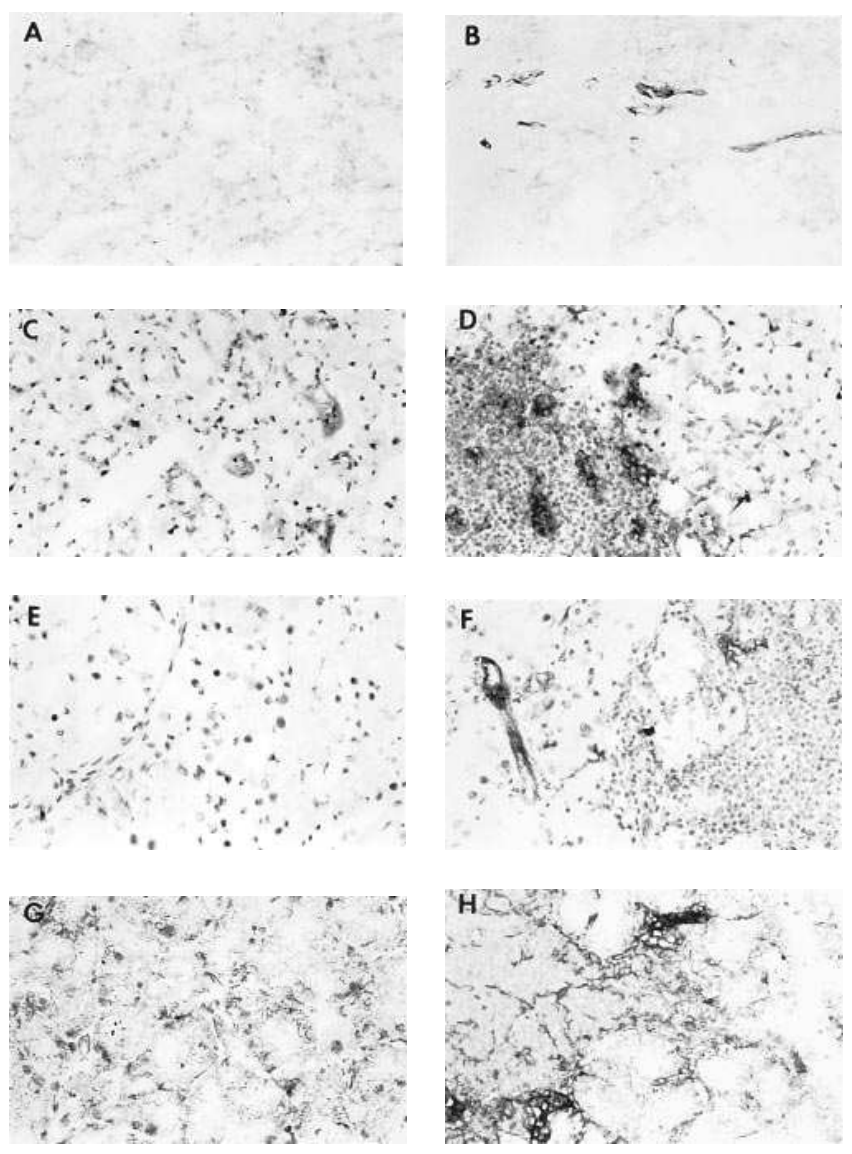

Figure 6. Representative immunohistochemical stainings with VCAM-1 or ICAM-1. ( $A-D)$ Submandibular gland of a 12-wk-old sTNFR p55-h $\gamma 3$-expressing female NOD mouse. ( $A)$ VCAM-1 expression in an sTNFR p55-h $\gamma 3$-expressing mouse. (B) VCAM-1 expression in a transgene-negative littermate. (C) ICAM-1 expression in an sTNFR p55-hy3-expressing mouse. $(D)$ ICAM-1 expression in a transgene-negative littermate. $(E-H)$ Lacrimal gland of 18 -wk-old sTNFR p55-h $\gamma 3$-expressing female NOD mice. $(E)$ VCAM-1 expression in a sTNFR p55-h $\gamma 3$-expressing mouse. $(F)$ VCAM-1 expression in a transgene negative littermate. $(G)$ ICAM-1 expression in an sT-NFR p55-h $\gamma 3$-expressing mouse. $(H)$ ICAM-1 expression in a transgene-negative littermate.

mal glands, immunostainings for these adhesion molecules were performed on cryostat sections of sTNFR p55-hy3expressing NOD mice and their transgene-negative littermates. As shown in Fig. 6, the expression level of VCAM-1 and ICAM-1 are clearly reduced in lacrimal glands of male and in submandibular glands of female sTNFR p55-hy3expressing NOD mice. Quantification of these findings revealed a reduction by $40-80 \%$ of vessels expressing these cell adhesion molecules (Fig. 7).

\section{Discussion}

Pancreatic $\beta$ cell destruction in NOD mice leading to IDDM has been extensively investigated so far (22). However, only a few data are available on the pathogenesis of tissue destruction in submandibular salivary and lacrimal gland destruction of these mice. The NOD mouse has been proposed as a valuable animal model for Sjögren's disease in humans for several rea-

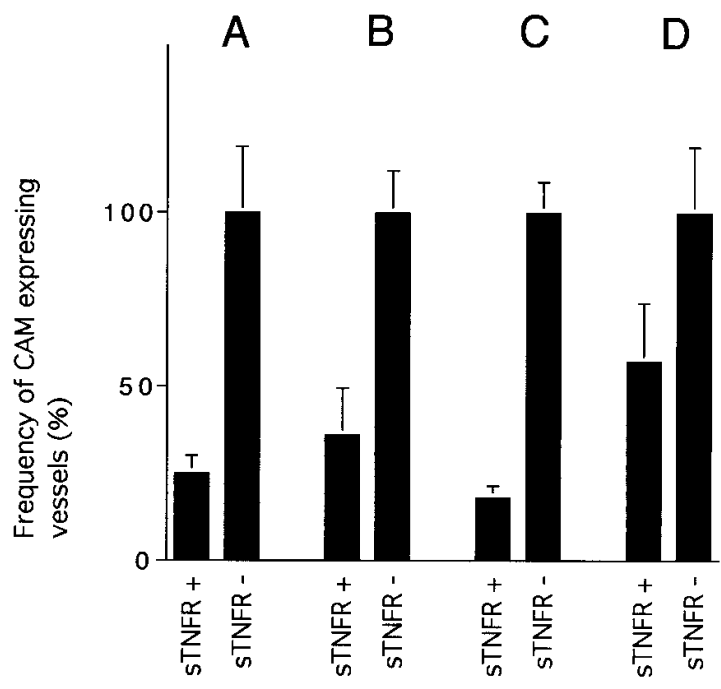

Figure 7. Quantitative evaluation of VCAM-1 and ICAM-1 expression on blood vessels in submandibular and lacrimal glands of sTNFR p55-h $\gamma 3$-expressing NOD mice $(s T N F R+)$ and their transgene-negative littermates $(s T N F R-)$. The number of blood vessels expressing VCAM-1 or ICAM-1 was determined on the respective immunohistochemical stained tissue sections. The values were normalized (mean infiltration of transgene negative littermates $=100 \% \pm$ SEM).

VCAM-1 $(A)$ and ICAM-1 $(B)$ expression in submandibular glands of 12-wk-old female NOD mice. VCAM-1 $(C)$ and ICAM-1 $(D)$ expression in lacrimal glands of 18-wk-old male NOD mice. For each value, four or five animals were analyzed ( \pm SEM).

sons (e.g., NOD mice spontaneously develop mononuclear cell infiltration of the lacrimal and submandibular glands). Furthermore, the observed tissue damage is associated with functional changes in submandibular glands (23). In lacrimal glands of male NOD mice, the tissue destruction is even more pronounced, thus providing circumstantial evidence for a functional impairment of these glands as well. The analysis of the lacrimal glands revealed the surprising finding that male NOD mice show earlier and more pronounced infiltrates than females, a finding that was confirmed both in NOD mouse colonies kept under SPF, and under conventional conditions (data not shown). This observation may further point out the complexity of factors regulating autoimmune tissue infiltration.

The focus of the present study was to examine the contribution of TNF- $\alpha$ in tissue infiltration and destruction of these glands. First, we followed by in situ hybridization the appearance of TNF- $\alpha$-expressing cells in submandibular and lacrimal glands of NOD mice. Evidence for the presence of TNF $\alpha$ at the protein or mRNA level has been documented in virtually all inflammatory lesions analyzed (7). Therefore, it is not too surprising to have this gene expressed in the cellular infiltrates of affected lacrimal and submandibular glands (Figs. 1 and 2). However, several points deserve particular attention (e.g., when expression levels of the TNF- $\alpha$ gene in cells of the salivary gland infiltrates are compared with those in the spleen and lymph nodes, consistently higher signals on a per cell basis are found in salivary gland specimens). Together with the observation that $>90 \%$ of TNF- $\alpha$ mRNA-expressing cells are found in close contact with parenchymal cells, this may indicate local activation of these TNF- $\alpha$ mRNA-expressing cells. The observation of maximum frequencies of TNF- $\alpha$-express- 
ing cells in the cellular infiltrates at the onset of infiltration indicates the involvement of $\mathrm{TNF}-\alpha$ in the early stages of infiltration. Considering the relative abundance of CD4 T cells in the infiltrates of lacrimal and submandibular glands and the determined frequencies of TNF- $\alpha$ mRNA-positive cells within this subset, the majority of TNF- $\alpha$ mRNA-expressing cells are CD4 $\mathrm{T}$ cells. A similar conclusion was reached regarding inflammatory infiltrates in the pancreatic islets of Langerhans from NOD mice (24). TNF- $\alpha$ mRNA expression as assessed by RT-PCR in the human counterpart of sialadenitis, (i.e., Sjögren's disease) has also been reported recently in epithelial cells of affected salivary glands from patients with Sjögren's syndrome by Fox et al. (25). However, during the entire observation period, we were unable to demonstrate detectable levels of TNF- $\alpha$ mRNA by in situ hybridization in salivary gland epithelial cells in NOD mice.

The early appearance of TNF- $\alpha$ mRNA-expressing cells in the infiltrates of affected salivary glands, together with the reduced (or even absent) mononuclear infiltration of submandibular glands in transgenic NOD mice expressing an sTNFR p55-h $\gamma 3$ are consistent with a central role for TNF in the progression of sialadenitis in NOD mice. The appearance of TNF- $\alpha$ mRNA in cellular infiltrates at early stages of disease provides circumstantial evidence for an involvement of this cytokine also in initiation of disease. However, it cannot be completely excluded that nonautoimmune mechanisms also cause initial tissue damage. The precise mode of action of TNF in the pathogenesis of sialadenitis remains to be determined. One mode of action may include induction of adhesion molecules on the vascular endothelium in the salivary glands. An involvement of TNF- $\alpha$ in the upregulation of several adhesion molecules including ICAM-1, VCAM-1, and MAdCAM-1 has been demonstrated on endothelial cells cultured in vitro (8). Elevated ICAM-1 (26) and VCAM-1 (27) levels on high endothelial venule-like structures have also been recently reported in infiltrated areas of submandibular glands of NOD mice. In addition, we found expression of both cell adhesion molecules in infiltrated lacrimal glands of male NOD mice (Fig. 6, $B$ and $D)$. The finding that the decreased infiltration of submandibular and lacrimal glands in sTNFR p55-hy3-expressing mice is paralleled by reduced expression of cell adhesion molecules on blood vessels (compare Figs. 5 and 7) suggests that TNFinduced endothelial changes are correlated with the extent of mononuclear infiltration, and thus, decreased upregulation of these cell adhesion molecules may represent one mechanism of protection in sTNFR p55-h $\gamma 3$-expressing NOD mice.

Alternatively, but not mutually exclusive, $\mathrm{TNF}-\alpha$ acting synergistically with IL-1 may be more directly involved in tissue destruction than has been proposed for selective $\beta$ cell destruction in NOD mice (28) through either direct cytotoxic effects on TNF- $\alpha$-sensitive target cells, or more indirectly; e.g., through activation of an inducible NO synthetase. Recent results from an extensive study by Yang et al. (12), however, seem to argue against a crucial role of $\mathrm{TNF}_{-} \alpha$ in the induction of sialadenitis in NOD mice; whereas, intraperitoneal administration of neutralizing anti-TNF- $\alpha$ mAb during the first $3 \mathrm{wk}$ of life lead to an almost complete inhibition of insulitis in 32wk-old female NOD mice, the incidence of sialadenitis was not affected in treated mice. Although this may be due to a differential expression pattern of adhesion molecules in pancreas and salivary glands, other factors such as suboptimal availability of anti-TNF mAb in salivary glands, or an inappropriate time period of anti-TNF- $\alpha$ administration cannot be completely excluded. In particular, sTNFR p55-h $\gamma 3$-expressing mice consistently show high serum concentrations of the transgene before appearance of first histological signs of infiltration (see Methods) and already at birth, they are able to neutralize considerable amounts of bioactive TNF- $\alpha$.

In conclusion, we have shown that $\mathrm{TNF}-\alpha$ is expressed at early stages in salivary and lacrimal gland infiltration of NOD mice. Furthermore, neutralization of TNF- $\alpha$ by transgenic expression of an sTNFR p55-h $\gamma 3$ results in significantly lower infiltrations to these glands. This protection is associated with decreased expression of the cell adhesion molecules VCAM-1 and ICAM-1. These results suggest a central role of TNF- $\alpha$ in initiation and progression of salivary and lacrimal gland infiltration in NOD mice and provide evidence that neutralizing sTNFR p55-h $\gamma 3$ may have beneficial effects on the course of autoimmune tissue infiltration and destruction.

\section{Acknowledgments}

We thank Dr. T. Schaffner for assistance in morphometric analysis of tissue sections, Dr. P. Vassalli for allowing use of the soluble TNFreceptor transgenic mice, Dr. H.J. Hedrich (Zentralinstitut für Versuchstierzucht, Hannover, Germany) for helpful discussions on the genetics of the sTNFR p55-hy3 NOD mice, Therese Périnat, Irina Vogt, and Marianne Bärtschi for technical assistance, Steven Merlin for running the FACSVantage ${ }^{\circledR}$ and for invaluable comments on the manuscripts, and Dr. T. Seebeck for discussion and support.

This work was supported by grants 31-43495.95 and 31-42275.94 of the Swiss National Science Foundation to C. Mueller and I. Garcia, respectively.

\section{References}

1. Pozzilli, P., A. Signore, A.J. Williams, and P.E. Beales. 1993. NOD mouse colonies around the world-recent facts and figures. Immunol. Today. 14:193-196.

2. Jabs, D.A., and R.A. Prendergast. 1994. Murine models of Sjogren's syndrome. Adv. Exp. Med. Biol. 350:623-630.

3. Humphreys Beher, M.G., Y. Hu, Y. Nakagawa, P.L. Wang, and K.R. Purushotham. 1994. Utilization of the non-obese diabetic (NOD) mouse as an animal model for the study of secondary Sjogren's syndrome. Adv. Exp. Med. Biol. 350:631-636.

4. Goillot, E., M. Mutin, and J.L. Touraine. 1991. Sialadenitis in nonobese diabetic mice: transfer into syngeneic healthy neonates by splenic $\mathrm{T}$ lymphocytes. Clin. Immunol. Immunopathol. 59:462-473.

5. Miyagawa, J., T. Hanafusa, A. Miyazaki, K. Yamada, H. Fujino-Kurihara, H. Nakajima, N. Kono, K. Nonaka, Y. Tochino, and S. Tarui. 1986. Ultrastructural and immunocytochemical aspects of lymphocytic submandibulitis in the non-obese diabetic (NOD) mouse. Virchows Arch. 51:215-225.

6. Sugihara, T., Y. Yoshimura, and O. Tanaka. 1989. Ultrastructural and immunoelectron microscopic studies on infiltrating mononuclear cells in lymphocytic submandibulitis in NOD mice. Histol. Histopath. 4:397-404.

7. Vassalli, P. 1992. The pathophysiology of tumor necrosis factors. Annu. Rev. Immunol. 10:411-452.

8. Sikorski, E.E., R. Hallmann, E.L. Berg, and E.C. Butcher. 1993. The Peyer's patch high endothelial receptor for lymphocytes, the mucosal vascular addressin, is induced on a murine endothelial cell line by tumor necrosis factor- $\alpha$ and IL-1. J. Immunol. 151:5239-5250.

9. Pukel, C., H. Baquerizo, and A. Rabinovitch. 1988. Destruction of rat islet cell monolayers by cytokines: synergistic interactions of interferon-gamma, tumor necrosis factor, lymphotoxin and interleukin-1. Diabetes. 37:133-136.

10. Cleveland, J.L., and J.N. Ihle. 1995. Contenders in FasL/TNF death signaling. Cell. 81:479-482.

11. Jacob, C.O., S. Aiso, S.A. Michie, H.O. McDevitt, and H. Acha-Orbea 1990. Prevention of diabetes in nonobese diabetic mice by tumor necrosis factor (TNF): similarities between TNF- $\alpha$ and interleukin1. Proc. Natl. Acad. Sci. USA. 87:968-972.

12. Yang, X.D., R. Tisch, S.M. Singer, Z.A. Cao, R.S. Liblau, R.D. Schreiber, and H.O. McDevitt. 1994. Effect of tumor necrosis factor alpha on insulin-dependent diabetes mellitus in NOD mice. I. The early development of autoimmunity and the diabetogenic process. J. Exp. Med. 180:995-1004. 
13. Jacob, C.O., S. Aiso, R.D. Schreiber, and H.O. McDevitt. 1992. Monoclonal anti-tumor necrosis factor antibody renders non-obese diabetic mice hypersensitive to irradiation and enhances insulitis development. Int. Immunol. 4: 611-614.

14. Garcia, I., Y. Miyazaki, M. Araki, R. Lucas, G.E. Grau, G. Milon, Y. Belkaid, C. Montixi, W. Lesslauer, and P. Vassalli. 1995. Transgenic mice expressing high levels of soluble TNF-R1 fusion protein are protected from lethal septic shock and cerebral malaria, and are highly sensitive to Listeria monocytogenes and Leishmania major infections. Eur. J. Immunol. 25:2401-2407.

15. Wicker, L.S., J.A. Todd, and L.B. Peterson. 1995. Genetic control of autoimmune diabetes in the NOD mouse. Annu. Rev. Immunol. 13:179-200.

16. Flaherty, L. 1981. Congenic strains. In The Mouse in Biomedical Research. Vol. 1. H.L. Foster, J.D. Small, and J.G. Fox, editors. Academic Press, Inc., Orlando, FL. 215-222.

17. Sepulveda, A.R., M.J. Finegold, B. Smith, B.L. Slagle, J.L. DeMayo, R.F. Shen, S.L.C. Woo, and J.S. Butel. 1989. Development of a transgenic mouse system for the analysis of stages in liver carcinogenesis using tissue-specific expression of SV40 large T-antigen controlled by regulatory elements of the human $\alpha$-1-antitrypsin gene. Cancer Res. 49:6108-6117.

18. Hogan, M.M., and S.N. Vogel. 1993. Measurement of tumor necrosis factor $\alpha$ and $\beta$. In Current Protocols in Immunology. Vol. 1. J.E. Coligan, A.M. Kruisbeek, D.H. Margulies, E.M. Shevach, and W. Strober, editors. John Wiley and Sons, Inc., New York. 6.10.1-6.10.5.

19. Pennica, D., J.L. Hayflick, T.S. Bringman, M.A. Pallading, and D.V. Goeddel. 1985. Cloning and expression in Escherichia coli of the DNA for murine tumor necrosis factor. Proc. Natl. Acad. Sci. USA. 82:6060-6064.

20. Mueller, C., H.K. Gershenfeld, C.G. Lobe, C.Y. Okada, R.C. Bleackley, and I.L. Weissman. 1988. A high proportion of T lymphocytes that infiltrate H-2 incompatible heart allografts in vivo express genes encoding cytotoxic cell-specific serine proteases, but do not express the MEL-14-defined lymph node homing receptor. J. Exp. Med. 167:1124-1136.

21. Klinman, D.M., and T.B. Nutman. 1994. ELISPOT assay to detect cytokine-secreting murine and human cells. In Current Protocols in Immunology. Vol. 1. J.E. Coligan, A.M. Kruisbeek, D.H. Margulies, E.M. Shevach, and W. Strober, editors. John Wiley and Sons, Inc., New York. 6.19.1-6.19.8.

22. Castano, L., and G.S. Eisenbarth. 1990. Type-I diabetes: a chronic autoimmune disease of human, mouse and rat. Annu. Rev. Immunol. 8:647-679.

23. Hu, Y., Y. Nakagawa, K.R. Purushotham, and M.G. Humphreys Beher. 1992. Functional changes in salivary glands of autoimmune disease-prone NOD mice. Am. J. Physiol. 263:607-614.

24. Held, W., H.R. MacDonald, I.L. Weissman, M.W. Hess, and C. Mueller. 1990. Genes encoding tumor necrosis factor $\alpha$ and granzyme A are expressed during development of autoimmune diabetes. Proc. Natl. Acad. Sci. USA. 87: 2239-2243.

25. Fox, R.I., H. Kang, D. Ando, J. Abrams, and E. Pisa. 1994. Cytokine mRNA expression in salivary gland biopsies of Sjögren's syndrome. J. Immunol. 152:5532-5539.

26. Faveeuw, C., M.C. Gagnerault, and F. Lepault. 1994. Expression of homing and adhesion molecules in infiltrated islets of Langerhans and salivary glands of nonobese diabetic mice. J. Immunol. 152:5969-5978.

27. Yang, X.D., S.A. Michie, R. Tisch, N. Karin, L. Steinmann, and H.O. McDevitt. 1994. A predominant role of integrin $\alpha 4$ in the spontaneous development of autoimmune diabetes in nonobese diabetic mice. Proc. Natl. Acad. Sci. USA. 91:12604-12608.

28. Kolb, H., V. Kolb-Bachofen, and O. Roep. 1995. Autoimmune versus inflammatory type I diabetes: a controversy? Immunol. Today. 16:170-172. 